\title{
[Re] pensar as derrotas no partido político: instrumentos gramscianos para uma análise
}

Rodrigo Francisco Maia ${ }^{1}$

\section{Resumo:}

Este trabalho tem como objetivo fornecer uma discussão a respeito da concepção gramsciana sobre o partido político, entendido como organização de classe, tomando as concepções de Gramsci a respeito das derrotas que poderiam acometer uma organização político-partidária. Tomamos as organizações partidárias comunistas italiana e portuguesa como exemplos histórico-concretos no desenvolvimento deste trabalho. Nos interessa destacar a discussão que Antonio Gramsci realizou a respeito das derrotas: prática, ideológica e política.

Palavras-chave: Gramsci; partidos políticos; derrota prática; derrota ideológica; derrota política.

\section{[Re]thinking political party defeats: gramscian instruments for an analysis}

\begin{abstract}
:
This artcile aims to provide a discussion about the gramscian conception regarding political parties, understood as a class organization, taking the gramscian conception about defeats that could affect a political party. We have the italian and the portuguese communist parties as historical examples in this work. The interest is to indicate the Antonio Gramsci's reflexion realized specifically about the practical, ideological and political defeats.
\end{abstract}

Key words: Gramsci; Political parties; practical defeat; ideological defeat; political defeat.

\section{Introdução}

Gramsci teorizou que para a análise concreta da correlação de forças é preciso ter em conta, metodologicamente, três níveis: 1) a relação das forças sociais com a estrutura das forças produtivas em desenvolvimento; 2) a relação das forças políticas (do nível econômicoimediato, o que indicamos como o nível da consciência de classe em si, e o

${ }^{1}$ Doutorando em ciências políticas na Brunel University London. Pesquisa apoiada pela Capes-Brasil, code o01. E-mail: framaiari@gmail.com. 
da consciência de classe para si, ou o nível conjuntural da hegemonia); 3) e a relação das forças militares (com diferença entre o momento militar stricto sensu e o político-militar) (GRAMSCI, 2014, p. 1.583).

Ademais, Gramsci distingue o espontaneísmo de um movimento de consciente e orientado, sendo o primeiro um erro, e o segundo a verdadeira política de massas das classes subalternas (2014, p. 329). A concepção hegeliana indica que "A consciência-de-si é em si e para si quando e porque é em si e para si para uma Outra” (HEGEL, 1992, p. 126), nesse sentido tomamos a ideia de que o partido político das classes subalternas, como um organismo vivo e consciente de seu propósito, age em si segundo sua classe social, e também para si ao agir para a generalidade das classes.

Pretendemos dar destaque ao segundo nível da correlação de forças, as forças políticas, âmbito no qual o partido pode atuar como mediador das concepções de classe, ainda que na qualidade do senso comum, que passam do nível imediato ao nível organizativo: relativo àquilo que Gramsci teorizou como a autoconsciência e a organização alcançadas pelos grupos sociais.

Gramsci, em suas notas sobre Machiavelli, forneceu uma releitura e uma atualização sobre o papel do soberano na política, o príncipe, mas não mais o indivíduo. A novidade gramsciana reside na ideia de que a constituição do poder político deve estar envolta na forma do partido político: um organismo social que contém a complexidade e a particularidade da classe a qual pertence (GRAMSCI, 2014, p. 1.558).

$\mathrm{O}$ pensamento de Gramsci, registrado nos Cadernos do cárcere e em suas correspondências pessoais e políticas, sobre o partido político indica a ideia de um organismo prático da classe a qual pertence com o objetivo de promover a transformação das condições de vida da classe, além do mais, a transformação do conjunto das classes de uma sociedade a partir da revolução das bases e estruturas que regem o funcionamento das relações internas desta sociedade (GRAMSCI, 2014).

Tal transformação social, que passa da ação coletiva de uma classe para a generalidade das classes sociais, pode ser entendida como um movimento de mudança radical das classes trabalhadoras em si e para si. Hegel na Fenomenologia do espírito (1992), também Marx e Engels no Manifesto do partido comunista (2008), concebem a potencialidade da generalização da transformação social, ainda que cada um a seu modo, mas ambos com perspectivas metodológicas aproximadas - elemento importante, de caráter metodológico e político, para se entender em Gramsci a capacidade do partido político ser instrumento de produção de uma nova sociedade, a qual pode ser gerida já em seu interno. 
Sendo então o partido um organismo vivo orientado para a prática da transformação social, no conjunto das relações de força, nas disputas e nas tentativas de obter hegemonia, o mesmo pode vir a sucumbir derrotas no processo de busca pela afirmação da vontade coletiva. Gramsci também conceituou que o partido pode sofrer derrotas em três níveis: o prático (isolamento), o ideológico (reformismo) e o político (morte do partido) (MAIA, 2017; GRAMSCI, 2004, p. 132)². Além do fato de que o partido pode se conduzir às derrotas, Gramsci alerta que as classes tradicionais estão interessadas em impedir que novas formas de vontade coletiva se expressem na sociedade civil (GRAMSCI, 2014, p. 1.560).

Nesse sentido, este artigo busca oferecer algumas ideias a respeito da concepção gramsciana sobre o partido político e suas ações que, eventualmente, podem resultar em derrotas. Assim, admitimos que é possível encontrar em Gramsci o nexo entre a necessidade do Partido como mediador, como intelectual orgânico das classes trabalhadoras, e que desse fator resulta seu metabolismo interno, isto é, sua sustentação contra os três níveis de derrota.

Contra a concepção liberal burguesa de partido que não representa as próprias classes e que reforça o poder da burocracia, é preciso uma nova força para organização das classes, inspirada na história: a concepção gramsciana a respeito das derrotas prática, política e ideológica pode ser um contributo histórico para uma nova atuação político-partidária (GRAMSCI, 2014).

Observando o partido em suas estruturas internas, mas também sua existência em relação a classe que pertence e ao conjunto da sociedade, ou seja, o partido em si e o partido para si, o artigo prossegue acrescentando elementos sobre a dinâmica partidária no estado integral.

Enfim, dois exemplos históricos são vistos de modo a fornecer uma interpretação a respeito das derrotas sofridas por organizações de grande importância no espaço da esquerda comunista, o Partido Comunista Italiano e o Partido Comunista Português. Ainda que com particularidades e dinâmicas históricas próprias, os dois partidos sofreram diferentes derrotas que podem ser interpretadas a partir das ideias oferecidas por Antonio Gramsci a respeito das derrotas prática, ideológica e política.

\section{Sobre o partido em Gramsci}

Seria possível considerar que para Gramsci o partido político é um meio termo entre a grande e a pequena política? No terreno da pequena

2 Em seu Escritos políticos, Gramsci (2004) discute através de cartas com Palmiro Togliatti quais seriam as possibilidades de derrotas do Partido Comunista da Itália nos anos 1920, indicando os três diferentes níveis e tipos de derrotas que poderiam levar à falência total do partido no âmbito nacional. 
política, o partido estaria imerso num sistema de relações quotidianas que sustentam e dão continuidade ao sistema existente. Gramsci indica que, no mundo moderno, este é um terreno de lutas praticamente necessário e trata-se da atuação partidária na esfera parlamentar, o que significa inclui lidar com as regras do jogo, a política de corredor e as intrigas.

Diferente é o espaço da grande política, a preocupação com o novo, a preocupação com dinâmicas políticas que estão relacionadas com a sustentação da estrutura de poder. A grande política está ligada também às questões internacionais.

Gramsci tem a perspectiva histórica como terreno de sua argumentação. Nesse sentido, o exercício da hegemonia na grande política é visto de acordo com a classe que conquistou e mantém o exercício do poder político. A continuidade do sistema depende do equilíbrio de forças internas e externas. Assim, o partido das classes subalternas está preocupado com a reversão da correlação de forças, historicamente favorável às classes dominantes, de modo tal que uma de suas tarefas é recolocar o debate da grande política em tais termos, fornecendo os elementos da grande política (a criação do novo) não como uma política parlamentar, mas sim como uma necessidade coletiva: "È pertanto grande política il tentare di escludere la grande política dall'ambito interno della vita estatale e di ridurre tutto a piccola política" (GRAMSCI, 2014, p. $1.564)^{3}$.

Sendo um instrumento de organização da classe, o partido político, diz Gramsci, pode ser comparado àquilo que é o estado na sociedade política, mas na sociedade civil, ou seja, a função do partido é tratar de questões de hegemonia na sociedade civil, funcionando como um instrumento capaz de portar sua classe ao poder e ao exercício da hegemonia em diferentes áreas (um novo plano econômico, uma nova moral, etc.), fomentando a criação de uma nova concepção de mundo e uma nova vontade coletiva, sendo também um instrumento das classes subalternas na sociedade política, enfim, um instrumento do estado integral (2014, p. 1.522).

Para isso, o partido está encarregado de uma missão técnica, a qual é essencial para que possa ocupar uma posição favorável nas disputas, na guerra de posição, na esfera da cultura, da política e da economia: a educação e organização da classe em momentos de paz e em torno de seus interesses (2014, p. 1.567). Como indicado por Peter Thomas (2009: 149), a guerra de posição é uma estratégia realista diante do confinamento provocado pela burguesia, logo, uma estratégia desde uma posição subordinada.

3 "É, portanto, grande política a tentativa de exclusão da grande política do âmbito interno da vita estatal e a redução de tudo à pequena política" (tradução livre nossa). 
A organização da classe em torno de seus interesses, através do instrumento político que é o partido, permite que se amplie o alcance da organização e que, então, tais interesses passem a abarcar também outros grupos sociais subalternos em oposição aos partidos que atuam em vasta escala impedindo a formação do novo.

Como diz Thomas (2009), a guerra de posição condiz com as possibilidades reais das classes subordinadas para enfrentarem de modo realista e com uma estratégia o confinamento ao qual estão submetidas, e não um fim em si.

"War of position" in Gramsci's conception, just as for Lenin and Trotsky, was not a programmatic strategy that he recommended be adopted by the proletariat. Rather, he recognised it as a technique of nascent 'biopower' deployed by the bourgeoisie, and to which the proletariat, subalternly confined in bourgeois civil society, was constrained to respond with a realistic political strategy. (THOMAS, 2009, p. 150)4

$\mathrm{Na}$ análise de fatos históricos, Gramsci indicava que era preciso distinguir entre o permanente e o ocasional, como entre o estado e o governo, a estratégia e a tática. Um estudo sobre o partido, portanto, inclui necessariamente uma busca pela compreensão das condições históricas que levam ao seu nascimento, sua composição social, programa político e suas ações. Neste artigo a preocupação se dirige para os partidos de tradição marxista. As teorizações a respeito do partido como organismo de classe não estão totalmente sistematizadas nas obras de Marx, ainda que sua militância seja um ponto de referência, mas em Gramsci e outros militantes da tradição marxista o debate sobre o partido se encontra mais desenvolvido e são baseados na tradição político-filosófica anterior.

O conceito de partido, no entanto, aparece modelado muito mais nos escritos de Gramsci do que em Marx - o que indica a necessidade de ressignificar cada autor ao seu contexto. Pensar hoje a atuação do partido como mediador orgânico das e nas classes trabalhadoras é fundamental para a vitória nos três níveis apresentados - vitórias que se fazem urgentes e que passam pela questão de se [re]pensar o partido.

Há uma interconexão entre os níveis prático, ideológico e político na vida de um partido, e estão a todo momento submetidos às táticas e estratégia do partido num determinado momento. $\mathrm{O}$ organismo das classes subalternas é o agente que expande a ideologia ao nível da consciência

\footnotetext{
4 “'Guerra de posição', na concepção de Gramsci, como também para Lênin e Trotsky, não era a estratégia programática que ele recomendava ser adotada pelo proletariado. De fato, ele a reconhecia como uma técnica do nascente 'biopoder' implantado pela burguesia, e para o qual o proletariado, subalternamente confinado na sociedade civil burguesa, estava constrangido a responder com uma estratégia política realista" (tradução livre nossa). Peter Thomas também oferece uma discussão mais elaborada acerca das variações conceituais da guerra de posição em suas formas ofensiva e defensiva.
} 
para-si, de classe, superando os limites corporativos e buscando desempenhar uma ação particular de grande alcance no conjunto da sociedade que atua.

\section{Questões organizativas no partido}

A ressignificação histórica do objeto partido é, portanto, um passo fundamental no estudo sobre partidos, para que as diferentes formas de partidos possam ser apreendidas e confrontadas em seus determinados contextos de criação, desenvolvimento, composição e ação. Tal é o aspecto fundamental: o respeito aos conceitos pois, de fato, os partidos [comunistas] tal como o Partido Comunista Italiano, o Partido Comunista Português o Partido Comunista Brasileiro, o Partido Comunista da União Soviética, foram postos à prova de mediar a consciência em si e a para si, o que significou assumir posições a respeito da cultura, da religião, das artes, da economia, etc., em contextos sociais particulares, mas todos conexos através da ideia de construção de uma vontade coletiva e transformação social radical.

A cultura e a política no mundo do trabalho são vivíssimas e contraditórias, o partido não está imune aos seus efeitos e desenvolvimentos. A estratégia da revolução socialista contém a necessidade de realização de mediações históricas: apreensão das lições históricas com respeito a particularidade e ao contexto. Porém, se à força as bocas se calam, só com a morte as mentes se apagam. Muitos foram os partidos que sucumbiram à crise orgânica de representação, o que Gramsci caracteriza como responsabilidade dos setores dirigentes, configurando uma crise de autoridade no partido. "I partiti nascono e si costituiscono in organizzazione per dirigere la situazione in momenti storicamente vitali per le loro classi" (GRAMSCI, 2014, p. 1.604)5.

Os organismos das classes trabalhadoras são, portanto, vivos e possuem sua materialidade, seus militantes e sua ideologia: o partido atuando como mediação é o organismo no qual se desenvolvem as potencialidades dos intelectuais orgânicos das classes trabalhadoras. Nem sempre o partido está apto a adaptar-se às novas tarefas e momentos históricos, ainda que cada caso seja particular e tenha dinâmicas próprias. Nesse sentido, o momento histórico é importante e uma constante atualização do partido se faz necessária para que anacronismos sejam evitados e, então, o partido sobreviva às crises.

Mas, de que forma pode um partido manter-se em consonância com seu tempo e com sua materialidade? Em geral, o partido pensado por

5 "Os partidos nascem e se constituem em organizações para dirigir a situação em momentos historicamente vitais para sua própria classe" (tradução livre nossa). 
Gramsci tem a missão de ter seus membros formados e em contínua formação intelectual dentro de seu mecanismo. $\mathrm{O}$ dirigente, o intelectual formado organicamente no partido, tem condições de pensar a realidade para além do sentido estrito econômico, corporativo, sendo capaz de orientar a ação militante também para as questões gerais, nacionais e internacionais (2014, p. 1.523).

Il partito politico, per tutti i gruppi, è appunto il meccanismo che nella società civile compie la stessa funzione che compie lo Stato in misura piú vasta e piú sinteticamente, nella società politica, cioè procura la saldatura tra intellettuali organici di un dato gruppo, quello dominante, e intellettuali tradizionali, e questa funzione il partito compie appunto in dipendenza della sua funzione fondamentale che è quella di elaborare i propri componenti, elementi di un gruppo sociale nato e sviluppatosi come "economico", fino a farli diventare intellettuali politici qualificati, dirigenti, organizzatori di tutte le attività e le funzioni inerenti all'organico sviluppo di uma società integrale, civile e politica. (GRAMSCI, 2014, p. 1.522) ${ }^{6}$

No interior do partido uma determinada dinâmica de funcionamento é indicada por Gramsci como necessária para a vitalidade da organização, é a manutenção da organicidade e a introdução dos novos elementos de base do partido em suas mais altas esferas. Gramsci caracteriza essa mobilidade organizativa como centralismo democrático, diferenciando o partido com bases e dirigentes orgânicos da estrutura de um estado, na qual prevalece o oposto ao centralismo democrático: o centralismo burocrático.

O intuito do centralismo burocrático é dar continuidade a um poder já estabelecido. O partido que visa a transformação age por outras vias e busca justamente implementar o novo e o "progressivo" (GRAMSCI, 2014, p. 1.635). O novo e progressivo advém dos intelectuais que são e fazem a organização das classes subalternas, são os intelectuais orgânicos. A conceitualização de Gramsci indica o lado oposto ao da dinâmica progressiva de um partido de tal gênero, em contraposição a crítica e autocrítica Gramsci coloca a racionalização, a abstração e a dedução como métodos inviáveis ao surgimento contínuo do novo.

$\mathrm{Na}$ realidade a existência de um partido tem motivação pela sua prática efetiva de combates, disputas e organização. Se trata então de uma

6 "O partido político, em todos os grupos, é, portanto, o mecanismo que na sociedade civil cumpre a mesma função que cumpre o estado em medida maior e mais sintética, na sociedade política, ou seja, procura a ligação entre intelectuais orgânicos de um dado grupo, o dominante, e intelectuais tradicionais, e esta função o partido cumpre, portanto, independentemente de sua função fundamental, que é aquela de elaborar os próprios componentes, elementos de um grupo social nascido e desenvolvido como "econômico", até que se transforme em intelectuais políticos qualificados, dirigentes e organizadores de todas as atividades e funções inerentes ao desenvolvimento orgânico de uma sociedade integral, civil e política" (tradução livre nossa). 
realidade animada para a questão da luta de classes (MARX, 2008). Nos Cadernos do cárcere, a questão aparece na forma da relação de forças, ou rapporti di forza, em italiano (2014, p. 1.561).

Quando estão postas à prova as táticas e a estratégia do partido, em confronto com outras forças, a relação de forças se verifica empiricamente através de como a ação, a atividade particular do partido, influência a dinâmica das classes sociais. Se faz justo então observar através de outros elementos o que Gramsci entendia por partido, o partido também é visto através dos termos machiavellianos sobre o príncipe - na leitura de Gramsci, o moderno príncipe.

Se o partido deve ter uma dinâmica progressiva e sempre em consonância com a realidade, mantendo uma estrutura renovada e fluída, o Príncipe na modernidade não deve ser a expressão de uma vontade singular, ao contrário, deve ser a expressão da vontade coletiva. O que determina a eficácia dessa fórmula gramsciana é a vontade, a necessidade que parte dos grupos subalternos e fornece uma "volontà collettiva riconosciuta e affermatasi parzialmente nell'azione” (2014, p. 1.558)7.

A motivação, portanto, do partido reside também em seu contrário: não deve ser um mecanismo organizativo que exprima em si e para si a figura de uma única expressão abstrata ou divina, além disso, evitando ação dentro de concepções econômico-corporativas. Ao não manter vivo seu ânimo é que o Príncipe passa ao campo das derrotas e deixa de ter sua função na criação do novo.

\section{As derrotas multinível}

Nos Escritos políticos, seleção de textos gramscianos, podem ser encontradas referências às questões de partido que aqui estão sendo discutidas. Entre tais referências são interessantes as que indicam os tipos de derrotas que um partido pode sofrer em momentos de crise e na correlação de forças. Vale notar que o debate que Gramsci está inserido contém uma ampla complexidade de forças políticas envolvidas e um terreno histórico que são cruciais em sua argumentação e que são suas reais motivações.

Escreveu Gramsci que, metodologicamente, é necessário observar que: "Ciò che è occasionale dà luogo alla critica política, ciò che è permanente dà luogo alla critica storico-sociale” (2014, p. 455) ${ }^{8}$. Nesse sentido, o estudo sobre a política partidária se localiza principalmente no

7 “(...) vontade coletiva reconhecida e afirmada parcialmente na ação” (tradução livre nossa).

8 "Aquilo que é ocasional dá espaço à crítica política, aquilo que é permanente dá espaço à crítica histórico-social” (tradução livre nossa). 
âmbito da crítica política, contudo, a ação do partido é voltada para a crítica histórico-social.

O debate gramsciano estava circundado pelo nascente e em desenvolvimento Partido Comunista da Itália. Contudo, as advertências de Gramsci perpassam em tempo e espaço e podem servir para uma discussão sobre as derrotas que vieram a arrefecer a esquerda comunista anos mais tarde. Havendo uma base comum em suas criações e adequações, os partidos da esquerda comunista possuem uma história em comum, de caráter internacional, e a conceituação gramsciana se aplica a essas organizações, visto que atuaram na direção da criação de uma nova moralidade, assegurando uma continuidade estratégica pela criação do novo, constituíram seus intelectuais orgânicos, disputaram posições.

As derrotas que as organizações sofreram possuem uma processualidade histórica e, ainda que não seja o objetivo deste artigo discutir as razões de tais derrotas e com respeito a todos os casos particulares, motivações se encontram naquilo que Gramsci caracterizou como crise de representatividade, ou crise orgânica da classe dirigente 9 .

Num dos textos dos Escritos políticos é possível encontrar uma carta de Gramsci ao dirigente do Partido Comunista, Palmiro Togliatti, a respeito das contradições do Partido Comunista da Itália:

Mas, se continuarmos a assumir as atitudes formalistas que temos assumido até agora (observe que isso vale para mim, para você, para Bruno, para Umberto, mas não para Amadeo), obteremos a finalidade oposta àquela que desejamos: a oposição se tornará de fato a representante do Partido e nós permaneceremos marginalizados, sofreremos uma derrota prática, talvez irremediável e que será inelutavelmente o início da nossa desagregação como grupo e de nossa derrota ideológica e política. (GRAMSCI, 2004, p. 132)

Da análise dos textos dos Escritos, é possível identificar que para Gramsci as derrotas, embora não sendo um dos conceitos mais destacados de sua elaboração, é parte constitutiva de sua análise da política. Em diferentes casos as discussões perpassam três diferentes tipos de derrotas, a prática, a ideológica e a política.

A caracterização da derrota prática vale para aspectos internos e também externos ao partido. Na prática, um partido é derrotado quando se encontra no isolamento, deslocado dos grupos subalternos e de sua base, bem como está marginalizado o grupo dirigente que até então estava consolidado e ora passa a ser substituído pela oposição. Nessa situação, o partido ainda tem sua base em conexão, está integrado pelos seus intelectuais orgânicos e há condições de prosseguir na cena nacional.

9 Nossa dissertação de mestrado busca discutir elementos que levaram os Partidos Comunistas da Itália e de Portugal às sucessivas derrotas nos anos de guerra fria (MAIA, 2017). 
O segundo tipo de derrota é a ideológica, que diz respeito a mudança de pensamento dentro do partido, a sua viragem verso novas concepções, podendo significar um passo em direção ao reformismo, no caso das organizações das classes subalternas antes empenhadas com a transformação radical da sociedade.

Alguns partidos sofreram não somente os dois tipos de derrotas anteriores, como também acumularam em sequência os dois tipos e somaram ainda um terceiro, a derrota política. $\mathrm{Na}$ história das organizações das classes subalternas, a derrota política significou o desmanche efetivo das organizações, as quais transformaram seus nomes, estratégia e táticas, reformularam suas bases e seus dirigentes.

As percepções de Gramsci diziam respeito ao Partido Comunista da Itália em tempos de duras lutas. Nesse sentido, hoje podem servir como instrumentos metodológicos interessantes para a caracterização de processos nos quais organizações das classes subalternas foram derrotadas, mais do que leituras que busquem resultados estáticos postfestum.

Expressivo foram os processos de transformação da esquerda em geral após o colapso do regime da União Soviética (dentro e fora da União Soviética diversas organizações sucumbiram aos problemas internos e à pressão externa). As perspectivas de conquista da hegemonia pelas classes subalternas pareciam ter chegado ao fim e o mundo neoliberal, globalizado, suplantaria a velha dualidade da guerra fria.

Como resulta das análises de David Harvey (1994), a derrota dos movimentos das classes trabalhadoras permitiu a continuidade do controle social dos grupos dirigentes a partir dos governos nos estados. Não apenas os Partidos Comunistas estavam longe dos governos e do exercício da busca pela hegemonia, como as organizações de base foram neutralizadas através da cooptação ou da coerção, para além das derrotas da esquerda comunista.

Dois serão os exemplos a seguir a respeito de uma leitura gramsciana sobre as derrotas sofridas por organizações das classes subalternas. A ideia é observar como tais partidos atuaram diante do quadro de transformações nacionais e internacionais marcadas pela integração dos países no âmbito da União Europeia. O primeiro exemplo, o do Partido Comunista Italiano (PCI), é de como os três níveis de derrotas podem ocorrer dentro de uma organização. O segundo, o do Partido Comunista Português (PCP), indica que embora o partido tenha sucumbido às derrotas prática e ideológica, ainda assim manteve sua unidade e existência política. 


\section{O PCI}

Gramsci indicou que a história dos grupos subalternos é desagregada, mas suas ações possuem muito valor ao se colocarem no combate às iniciativas dominantes (GRAMSCI, 2014). Justamente o partido no qual Gramsci militou podem ser empregadas as chaves de leitura das derrotas. Sepultado nos anos 1990, o PCI foi o maior partido comunista do ocidente em tempos de guerra fria e sua desagregação deu origem a diversas forças políticas que ainda hoje fazem menção às tradições comunistas, seja em termos democráticos ou revolucionários.

O PCI se encontrava dentro de um país sob ocupação nazista e norte-americana, e com as classes trabalhadoras do Norte tomando/ou prestes a tomar o poder em diversas regiões, nos anos finais da II Guerra Mundial. A guerra civil e o aprofundamento do caos eram iminentes. A reunificação do país e a escolha por uma saída pacífica não foram decisões tomadas apenas pela direção do PCI: desde os acordos de Yalta e Potsdam as áreas de influências estavam combinadas.

A democratização da Itália fazia parte da estratégia do PCI, e a escolha italiana pela democracia pode ser vista como um passo na caminhada estratégica dos comunistas, afinal, convinha às forças democráticas do país pôr fim ao regime fascista. Um conjunto de lutas e também de guerra de posição garantiram aos PCI um espaço decisivo nas transformações que, também através de referendum, portaram a Itália à via democrática (AGOSTI, 1999).

A passagem à democracia ocorreu através da aceitação por parte do PCI de depor as armas, de apaziguar os grupos subalternos e formar um governo de unidade nacional, a conhecida svolta ${ }^{10}$ (MAIA, 2017). Contudo, dentro das regras das instituições democráticas, outras forças políticas foram mais efetivas em conquistar espaços nas guerras de posição travadas ao longo dos anos de reconstrução do país. Assim, o PCI, passando a atuar dentro de um sistema democrática consolidado perdeu parte significativa de sua força (que estava em grande parte, e também de acordo com o momento de conflitos sociais intensos, em seus grupos armados e rebelados pelo país: os partigiani).

Além da consolidação do regime político em sua forma democrática, é importante notar que a retomada econômica da Itália se deu pela via do liberalismo econômico (através dos investimentos do Plano Marshall). Desse modo, sendo o PCI uma forma antagônica ao modelo de país que se desenvolvia, seu espaço na sociedade política nacional se deteriorou, do

10 A svolta di Salerno ficou conhecida na história do PCI como o momento decisivo da política dos comunistas italianos no fim da guerra, ao concordarem com a pacificação de um país a beira do caos (PCI, 1981). 
mesmo modo como sua força na sociedade civil havia sido transformada por conta da pacificação.

O PCI, portanto, nos anos 1950 e 1960, sofreu uma primeira derrota, a qual caracterizamos como prática, no sentido de que teve suas forças diminuídas de maneira significativa, passado a ser um partido com atuação minoritária após um processo de lutas de grande intensidade em todas as esferas sociais. Também se justifica a derrota do PCI pela sua adoção de uma via ao socialismo muito particular ao país, o que rendeu um relativo isolamento da organização em nível nacional e internacional, bem como na esfera da sociedade política se viu substituído no poder por forças democráticas que agiam dentro das estruturas capitalistas: a Democrazia Cristiana e o PSI (PCI, 1981; LIGUORI, 2009).

Com a intensificação do processo de integração dos países num espaço comum europeu e, ao mesmo tempo, com as investidas da União Soviética em países do chamado Leste europeu, o PCI passou não somente a se diferenciar das políticas comunistas em nível internacional, como também a combater o modelo soviético. Ainda no sentido da política internacional, a integração europeia foi tomada como efetivação prática do desenvolvimento democrático, em contrapartida ao modelo soviético. Assim, o partido lançou sua política da alternativa democrática, a qual lhe permitia a realização de alianças políticas com outras forças democráticas em atuação na sociedade política italiana, como os católicos e os socialistas num segundo momento, em busca de maiores liberdades democráticas.

Ainda que tendo sucumbido à derrota prática, o PCI continuava a ser um partido de massas na Itália, por isso também se justifica sua intensa e importante presença na cena política pós-Guerra. Contudo, era um partido que não tinha condições de obter maioria parlamentar através das ações eleitorais, ainda que essas fossem parte da guerra de posição travada pelo partido. O PCI adotou então a estratégia do compromesso storico, um meio de participar como um organismo das classes subalternas no jogo da democracia institucional italiana (PCI, 1981). Vale notar que a política do compromisso histórico ocorreu num momento em que o país passava por sérias dificuldades econômicas, e o PCI se comprometeu a ser uma força progressista.

De tal modo foi a participação dos comunistas italianos no contexto político institucional que, após o compromesso, a continuidade estratégica em transformação deu vida à política da democracia progressiva. Expressões da política democrática progressiva como via italiana ao socialismo, foi a formulação da política eurocomunista. 
O eurocomunismo não se deve somente ao PCI, pois foi formulado conjuntamente com outros partidos comunistas europeus no contexto da integração europeia.

E in questo quadro che l'Europa occidentale può e deve garantire, in forme nuove, il proprio sviluppo economico e ciò richiede la costruzione di nuovi rapporti sia con gli Stati Uniti, sia com l'Urss, e i paesi socialisti, sia com i paesi in via di sviluppo. Decisivo può dunque essere il ruolo mondiale di un'Europa occidentale democratica, indipendente e pacifica, che non sia né antisovietica né antiamericana ma si proponga al contrario di stabilire rapporti di amicizia e di collaborazione com questi e com tutti gli altri paesi. (BERLINGUER, 2013, p. 74) ${ }^{11}$

Dentro do PCI se aprofundou a compreensão sobre o nexo entre democracia e socialismo, como o socialismo sendo a expressão de uma democracia avançada que, na práxis política, passou a significar um maior respeito pelas regras constitucionais democráticas, isto é, por uma atuação dentro da legalidade, não combativa. Ao mesmo tempo, como indicava Gramsci, é preciso notar na análise de um partido quais são suas bases, quais são os aspectos conjunturais que regem a ação do partido. Vale também recordar que, para Gramsci, o moderno príncipe é m organismo vivo, no qual seus intelectuais se formam dentro do partido e atuam num sentido progressivo. Contudo, dentro do PCI as divisões internas cresciam.

A política de alianças desenhada ao longo de anos e posta em prática na realidade italiana e europeia não portou o PCI a ocupar uma posição favorável na guerra de posições, ao contrário, sua posição continuou a ser defensiva e dependente da política das forças dominantes do país. De tal modo fracassou a política de alianças, o que foi possível através de mudanças de concepções profundas sobre o sentido italiano para o socialismo, que designamos esse momento como uma derrota ideológica, na qual o partido não tinha condições de reverter o isolamento político ao passo que havia transformado sua estratégia.

Os anos que se seguiram foram intensos na vida do PCI. A ideia de um partido mediando as relações na sociedade civil e constituindo seus quadros para a criação do novo parecia ter cedido espaço a um partido diverso. A pequena política, de fato, passou a ser preponderante não apenas na vida do PCI, mas o sistema político italiano se mostrou consagrado ao terreno da intriga, do parlamentarismo em si. Como

11 "É nesse sentido que a Europa ocidental pode e deve garantir, em formas novas, o próprio desenvolvimento econômico e isso requer a construção de novas relações seja com os Estados Unidos, seja com a União Soviética, e os países socialistas, seja com os países em desenvolvimento. Decisivo pode ser, portanto, o papel mundial de uma Europa ocidental democrática, independente e pacífica, que e não seja nem antissoviética e nem antiamericana, mas se proponha, ao contrário, estabelecer relações de amizade e de colaboração com estes e com todos os outros países" (tradução livre nossa). 
observado por Peter Thomas (2009), a guerra de posição não deveria ser uma estratégia programática, mas sim uma política efetiva num determinado momento e com objetivos maiores. Contudo, o espaço da esquerda comunista reunida no PCI se reduziu e com isso também se reduziram seus objetivos.

As mudanças no mundo do trabalho indicavam a necessidade de novas táticas para a estratégia da revolução socialista, ou ainda, a aceitação da derrota da luta comunista. O PCI viveu uma década marcante. Buscou a aproximação com movimentos externos na comunidade europeia, mudou de direção diversas vezes (sem que isso significasse a inclusão de intelectuais orgânicos preocupados com a estratégia da transformação radical a partir de uma vontade coletiva), mudou de objetivos mais ainda. (AGOSTI, 1999).

Interessante é notar, porém, que o funcionamento do partido voltado para a via parlamentar não foi um aspecto de derrota, desde o ponto de vista eleitoral, pois o PCI conseguiu diversas vezes ascender aos governos e tinha representação no Parlamento Europeu (MAIA, 2017; PCI, 1981).

Estava em curso a crise do movimento comunista ${ }^{12}$. Não era uma crise restrita, circundante apenas às forças comunistas. Era uma crise que perpassava pelas diversas organizações das classes subalternas, que expressava décadas de abstenção às lutas em benefício da estabilidade democrática. Os estados operários degenerados da União Soviética caíram, a burocracia soviética prosseguiu em diversos governos de modo negociado e reciclado, mas na Itália os comunistas operaram um salto qualitativo mesmo sem chegar perto da possibilidade de transformação do país sob a direção das classes trabalhadoras. A guerra de posição empregada pelos comunistas desde Yalta e Potsdam havia chegado ao fim, com a crise dos comunistas.

As transformações da época da globalização foram vistas como a oportunidade para que, em conformidade com a crise mundial, a forma e o conteúdo comunista do PCI fossem sepultados e uma nova configuração partidária pudesse nascer. A partir das decisões do Tratado de Maastricht, que deram vida efetiva à hoje conhecida União Europeia, o PCI assumiu inteiramente a forma democrática liberal burguesa como seu programa (PAPA, 2006; AGOSTI, 1999; LIGUORI, 2009).

Muitos dos militantes comunistas não aceitaram, prosseguiram de outro modo a luta italiana pelo socialismo, uma luta que no espaço da UE não há possibilidade de ser unicamente nacional.

12 Como discutiu Perry Anderson em Um mapa da esquerda na Europa Ocidental. Rio de Janeiro: Contraponto, 1996. 
Menos de 24 horas depois da queda do Muro de Berlim, [Occhetto] aproveitou o momento de emoção para anunciar num discurso em Bolognina que pretendia mudar o nome do partido. (...) Fora de seu círculo mais próximo, a súbita iniciativa de Occhetto pegou todos de surpresa, até mesmo na liderança do PCI. (ANDERSON, 1996, p. 94)

A morte do PCI e o nascimento do Partito Democratico di Sinistra, no começo dos anos 1990, demonstrou o florescer de algo que já existia dentro do PCI. Foi o resultado de décadas de atuação em torno de estratégia de alianças democráticas e revisões ideológicas. A derrota, por fim, foi política. A esquerda comunista que continuou a história dos comunistas na Itália não tinha a mesma força e nem a mesma estrutura do PCI.

\section{O PCP}

O segundo exemplo que buscaremos fornecer vem do Partido Comunista Português, o PCP. Um partido de grande relevância em seu país, desde os anos de luta contra a ditadura, como também um partido fundamental na Revolução de 1974, e continua sendo uma importante organização dos grupos subalternos até hoje.

Com a estratégia da revolução democrática nacional o PCP emergiu como uma importante força política das classes trabalhadoras portuguesas na Revolução dos Cravos. Revolução que contou também com o Movimento dos Capitães e o Movimento das Forças Armadas sendo um dos grupos dirigentes, num país com uma trágica situação internacional na qual o ultracolonialismo ainda existia sob o último dos governos fascistas (ANDERSON, 1996).

A revolução portuguesa abriu o espaço para uma profunda transformação democrática do país. Necessária. Se tratava de pôr fim a última ditadura fascista, e também transformar as bases econômicas e moral do país. A transformação radical ocorreu. Ainda hoje podem ser vistos os resultados desta revolução.

A liquidação dos monopólios com as nacionalizações e a liquidação dos latifúndios com a reforma agrária, não só constituíram reformas econômicas e sociais de alcance histórico como constituíram medidas indispensáveis da defesa das liberdades e da democracia política. (CUNHAL, 2013, p. 43)

Da revolução emergiu o regime democrático acompanhado de uma profunda reforma política e econômica. $\mathrm{O}$ ânimo dos grupos subalternos se transformou junto com a revolução e dela foram o motor. Os próprios grupos subalternos impeliram suas lideranças a realizarem mais reformas sociais. De fato, a revolução democrática era aspecto essencial da estratégia dos comunistas portugueses, e a revolução colocou o partido à 
frente do processo - uma vitória programática fundamental para os grupos subalternos e uma lição para a esquerda em geral nos anos 1970.

Concluída a derrubada do poder ditatorial e introduzida a democracia, a primeira conquista estratégica do PCP havia sido cumprida. Com conflitos se passou ao momento da institucionalidade democrática, no qual as eleições, a promulgação da constituição e a normalidade foram demandas das direções das organizações políticas. Passou-se do processo revolucionário à implementação do processo democrático.

Diversas eram as organizações envolvidas na formulação de uma nova concepção e estado na sociedade política, como o PCP, o Movimento das Forças Armadas, o Partido Socialista, o Partido Social Democrata. O respeito à ordem internacional que vinha desde Yalta também foi mantido e garantido com apoio dos comunistas portugueses.

Dentro da lógica da sua estratégia de "revolução democráticanacional”, (...), não cabia qualquer processo de transformação global da sociedade, no sentido da abolição das relações capitalistas de produção, que subjazem ao estado capitalista. Mas tampouco excluía a luta pela melhor relação de forças possível, alicerçando-se em instrumentos de poder de forma a consolidar posições. (LOUÇÃ, 1985, p. 161)

Ainda contando com uma organicidade de grande relevância, o PCP, semelhante ao PCI, participou da construção de uma ordem estável, guiada pela constituição e, a exemplo da svolta italiana, com a pacificação das massas (inclusive pela força) (VARELA, 2011).

Meses de tentativas de apaziguamento da revolução se concluíram com a desintegração dos governos provisórios. Uma nova correlação de forças pesou a favor de novas organizações, especialmente a favor dos socialistas. Nesse momento, o PCP perdeu espaço, não se tornou uma força dominante e não podendo exercer uma hegemonia em amplos setores sociais a partir do estado. Dentro das regras do sistema democrático, o PSI se tornou uma força dominante.

Consequentemente, e com o esgotamento da revolução, o PCP sofreu a primeira derrota prática, se tornando uma força secundária nos governos nacionais, inviabilizando a continuidade de sua estratégia da revolução democrática como etapa ao socialismo e presenciando as forças adversárias assumirem os governos.

A mudança conjuntural fragilizou também a relação entre o PCP enquanto organização dos grupos subalternos e suas bases, as quais por anos atuaram de maneira clandestina e agora se encontravam diante de uma nova realidade. A pequena política ganhou espaço numa sociedade civil moralizada pelas conquistas de uma revolução, mas com direções políticas que não eram expressões da vontade coletiva. Através do sistema eleitoral novos governos se constituíram como continuidade da revolução 
na teoria, e como contrarrevolucionários na prática: se no processo revolucionário ocorreram nacionalizações, no período da estabilidade institucional ocorreram as privatizações (VARELA, 2011).

A integração europeia, em curso, voltou olhos para Portugal. Ainda que distante dos padrões econômicos europeus, o país contava com uma localização geoestratégica de grande importância para o continente europeu, contava com uma sociedade capaz de ser integrada às estruturas do mercado comum, e assim, com o Partido Socialista sendo uma das forças à frente, se iniciou o processo de integração de Portugal ao mercado comum (PAPA, 2006).

Mantendo-se com a mesma visão estratégica, ainda que numa nova conjuntura, o PCP refutou a integração europeia como uma possibilidade de continuidade da democratização do país (PCP, 1988). Contudo, sua atuação política se dava desde a posição minoritária e defensiva, buscando assegurar que conquistas da revolução não fossem revertidas - não tendo uma posição favorável na correlação de forças nacionais para lutar por mais conquistas revolucionárias.

A liberalização econômica ocorreu, poucos anos após a estabilidade democrática. Retorno do capital financeiro que havia sido expropriado, privatizações e um maior isolamento das forças representantes dos grupos subalternos caracterizavam o momento português nos anos 1980. Embora cada vez mais próximos da realidade europeia, o PCP recusava a opção italiana eurocomunista como uma saída prática e ideológica (CUNHAL, 1994).

Na estratégia dos comunistas o socialismo ainda era o objetivo a ser atingido. Mas a realidade que se construía indicava o inserimento de Portugal de modo subalterno dentro das estruturas do mercado comum. A forma do estado português era a democrática, mas com uma base material e econômica liberal (MAIA, 2017). A concepção do PCP se baseava na necessidade de continuar a defender a revolução, tendo como fundamento programático para suas táticas e estratégia o marxismo leninismo (PCP, 1988).

Nota-se que as direções políticas do partido basicamente possuem uma longa continuidade nos anos que seguiram à revolução. A nova realidade ainda era interpretada pelo PCP segundo um programa formulado antes da revolução (VARELA, 2011; MAIA, 2017; CUNHAL, 1994). As concepções programáticas do partido podem ser vistas em suas máximas extraídas dos congressos partidários. Em 1979, se passou da ideia de "com a democracia, pelo socialismo" para "com Portugal, ela democracia", mais tarde a novidade foi "Portugal, uma democracia avançada no limiar do século XXI” (PCP, 1988). 
Ainda que buscando uma adequação interpretativa da realidade de precarização do trabalho e feroz competição internacional, o terreno da democracia liberal inviabilizou a continuidade da estratégia socialista portuguesa. Soma-se o fato de que a própria imagem comunista sofria ataques naquele momento, no qual a União Soviética apresentava suas transformações estruturais rumo à liberalização dos mercados num contexto de fragmentação social.

Ao se encontrar impossibilitado de ser uma oposição ofensiva e de sair do isolamento, o PCP realizou mudanças programáticas que não tiveram efetividade. A integração portuguesa ao mercado europeu ocorreu em 1986, bem como o PCP não conseguiu mais ser uma expressão da vontade coletiva portuguesa. A partir desse contexto, caracterizamos o momento como o de uma segunda derrota, ideológica, fundada na incapacidade de implementação do novo, na impossibilidade de reverter a marginalização e o isolamento, somado ao fato do partido ter operado transformações programáticas significativas, sem êxito no desenvolvimento da guerra de posições que o partido ainda travava.

Integrado ao contexto internacional, o PCP formulou sua performance nos espaços da União Europeia através da participação crítica. O contexto eleitoral se tornou a regra do jogo político. Contudo, o PCP não se desintegrou, aliás continua a ter participação na cena política portuguesa, tanto nos espaços da pequena como da grande política, ainda que de forma minoritária em ambas. Mesmo sendo uma organização subalterna com um programa baseado, por décadas, na revolução em etapas, o PCP manteve em seu programa o socialismo como um objetivo estratégico. Consideramos, portanto, que o partido não sofreu uma derrota política.

\section{Considerações finais}

A conceituação gramsciana sobre o partido político nos oferece ferramentas para a compreensão de processos históricos que são significativos para os estudos sobre a esquerda em geral, em especial sobre a atuação das organizações das classes subalternas.

Este artigo buscou oferecer alguns elementos teóricos a respeito de uma concepção sobre o partido político no pensamento de Antonio Gramsci, desde sua fundamentação como expressão da vontade coletiva, sua necessária organicidade e contínua formação de quadros intelectuais, bem como sua atividade no contexto da guerra de posições.

Além disso, a experiência nas obras de Gramsci oferece uma caracterização sobre as derrotas que podem acometer as organizações das classes subalternas. As derrotas prática, ideológica e a política. 
De fato, as derrotas não correspondem a um único momento da atuação partidária, não se localizam em uma única ação desempenhada no contexto da guerra de movimentos ou da pequena política. Buscamos indicar, através de dois exemplos particulares, como podem ser interpretadas as performances de organizações das classes subalternas em realidades distintas, mas com similitudes, visto que, como salientou Gramsci, a crise orgânica de representatividade possui suas particularidades, mas em geral são consequências das tomadas de decisões pelos grupos dirigentes (GRAMSCI, 2014, p. 1.603).

Chama a atenção a importância da formulação gramsciana a respeito dos riscos que seu próprio partido sofria diante da crise política italiana que produziu o fascismo. Transformado ao longo do século XX, o PCI continuou a existir como um partido de orientação comunista por décadas, sendo o maior dos partidos comunistas do ocidente, porém, não evitando as sucessivas derrotas em diversos âmbitos, como no prático, no ideológico e no político. Diferente foi o PCP, que ainda existe, mas que em parte também sucumbiu às crises que assolaram diversas organizações da esquerda no momento final do breve século XX.

Certamente consideramos as diversas experiências revolucionárias vividas como lições para as gerações que se sucederam e como sendo particulares em seu íntimo. A formulação do novo ainda permanece e, segundo indicação gramsciana, o novo perpassa pela formulação do moderno Príncipe.

\section{Referências bibliográficas}

AGOSTI, A. Storia del PCI. Roma: Editori Laterza, 1999.

ANDERSON, P. Um mapa da esquerda na Europa Ocidental. Rio de Janeiro: Contraponto, 1996.

BERLINGUER, E. La passione non è finita. Editori Einaudi: Torino, 2013. CUNHAL, A. A Revolução Portuguesa: o passado e o futuro. Lisboa: Edições Avante!, 1994.

2013.

. O partido com paredes de vidro. São Paulo: Expressão Popular,

GRAMSCI, A. Quaderni del carcere. A cura de Valentino Gerratana. Torino: Einaudi Editore, 2014.

. Escritos políticos. Rio de Janeiro: Civilização Brasileira, 2004.

HARVEY, D. A condição pós-moderna. São Paulo: Loyola, 1994.

HEGEL, G. W. F. Fenomenologia do Espírito. 2. ed. Trad. Paulo Meneses. Rio de Janeiro: Editora Vozes, 1992.

LIGUORI, G. La morte del PCI. Roma: Manifestolibri, 2009. 
LOUÇÃ, F. A vertigem insurrecional: teoria e política do PCP na viragem de agosto de 1975. Revista Crítica de Ciências Sociais, Coimbra, n. 15/16/17, 1985 .

MAIA, R. I. F. A União Europeia e os comunistas: políticas do PCI e do PCP. Saarbrucken: Omniscriptum, 2017.

MARX, K., ENGELS, F. Manifesto do partido comunista. São Paulo: Expressão Popular, 2008.

PAPA, E. Storia dell'Unificazione Europea. Milano: Bompiani, 2006.

PCI. Le grandi scelte del PCI: sessanta anni nella storia. Roma: Fratelli Spada, 1981.

PCP. Proposta de Programa do Comitê Central para o XII Congresso do PCP. Portugal: Uma democracia Avançada no Limiar do Século XXI. Coimbra: Centro de Documentação 25 de Abril, 1988.

THOMAS, P. The Gramscian moment. Boston: Brill Editors, 2009.

VARELA, R. A história do PCP na Revolução dos Cravos. Lisboa: Bertrand Editora, 2011.

Como citar:

MAIA, Rodrigo Francisco. [Re]pensar as derrotas no partido político: instrumentos gramscianos para uma análise. Verinotio - Revista on-line de Fìlosofia e Ciências Humanas, Rio das Ostras, v. 25, n. 2, pp. 111-130, nov. 2019.

Data de envio: 22 jun. 2017

Data de aceite: 18 maio 2018 